\title{
Çoklu Görevler ile Bilişsel Kontrol Yetisi İlişkisinin Teorik Arka Planda İncelenmesi
}

\author{
Mine İMREN \\ Kırşehir Ahi Evran Üniversitesi Fen-Edebiyat Fakültesi, Psikoloji Bölümü, Kırşehir \\ mine.imren@ahievran.edu.tr \\ ORCID ID: https://orcid.org/0000-0003-0660-5396
}

Araştırma Makale

Revize Tarihi: 20.11.2019

DOI: $10.31592 /$ aeusbed.601061

Geliş tarihi: 03.08.2019

Kabul Tarihi: 22.11.2019

\author{
Atıf Bilgisi \\ İmren, M. (2019). Çoklu görevler ile bilişsel kontrol yetisi ilişkisinin teorik arka planda incelenmesi. Ahi Evran \\ Üniversitesi Sosyal Bilimler Enstitüsü Dergisi, 5(2), 389-407.
}

ÖZ

Dijital çağda kişiselleşen teknolojik bilgi iletişim ürünlerinin kullanımı oldukça yaygınlaşmıştır. Bu teknolojik ürünler sundukları çok sayıda bilgi ve fonksiyonlarla bireyleri çoklu görevlere yönlendirmektedir. Medya ürünlerinin eş zamanlı veya geçişler halinde kullanılması, çoklu medya görevi (ÇMG) olarak adlandırılan bir çoklu görev (ÇG) türüdür. Özellikle gençler tarafından sıklıkla kullanılan cihazların bilişsel düzeydeki etkileri hakkındaki çalışmalar daha fazla bilişsel kontrol yetisi üzerine yoğunlaşmış görünmektedir. Bilişsel kontrol, çoklu medya görevlerini sürdürmede elzem bir yeti olarak nitelendirilmektedir. Bilişsel kontrol yetisi ve ÇMG kullanım yoğunluğunu araştıran çalışmalardan elde edilen sonuçlar, genel olarak daha yoğun bir biçimde ÇMG kullanımı bildiren katılımcıların çeşitli bilişsel kontrol ögeleri ile ilgili görevlerde daha az başarılı olduğunu, günlük deneyimlerinin daha olumsuz olduğunu ve beyinde bilişsel kontrol yetisi ile ilgili bölgelerde yapısal değişimler ve farklı aktivasyon örüntülerine sahip olduklarını göstermiştir. Derlemenin amacı laboratuvar, öz bildirim ve beyin görüntüleme çaışmalarından elde edilen sonuçların alan yazında eksik olduğu gözlenen teorik arka plan dâhilinde incelenmesidir. Genel olarak bilişsel kontrol yetisi ve ÇMG arasında olumsuz yönde ilişki olduğunu ortaya koyan çalışma sonuçları literatürde yer alan çoklu görev teori ve hipotezleri çerçevesinde karşılaştırılarak tartışılmıştır.

Anahtar Kelimeler: Çoklu görev, çoklu medya görevi, bilişsel kontrol, yürütücü işlevler.

\section{Examining the Relationship between Multitasking and Cognitive Control Ability on the Theoretical Background}

\begin{abstract}
In the digital age, the use of personalized information and communication technology products has become widespread. These technological products have directed individuals to multitasking with various supplied information and functions. Using media products simultaneously or in transition is a type of multitasking (MT) named as media multitasking (MMT). Especially, the studies of the effects on cognitive level of devices frequently used by younger people appear focusing mainly on cognitive control ability. Cognitive control is considered as an essential ability in maintaining media multitasking. The results obtained from the researches investigating cognitive control ability and the intensity of MMT usage have shown that participants reporting more intensive usage of MMT in general, are less successful in tasks related to various cognitive control competences, their daily experience is more negative, and they have structural changes in areas related to cognitive control ability and different activation patterns in brain. The aim of this review is to examine the results obtained from the studies of laboratory, self-report and neuroimaging within the theoretical background which is regarded as being lack in the literature. The results of the studies which generally showed that MMT and cognitive control ability are correlated negatively have been compared and discussed in the light of multitasking theories and hypotheses.
\end{abstract}

Keywords: Multitasking, media multitasking, cognitive control, executive functions.

\section{Giriş}

Günden güne artan ve yaygınlaşan teknolojik yenilikler özellikle gençlerin oldukça ilgisini çekmektedir. Birçok kişiselleştirilmiş teknolojik cihaza sahip olan gençler, bu cihazları genellikle eş zamanlı olarak kullanmayı tercih etmektedir. Ülkemiz gençlerinin çoklu medya görevleri olarak adlandırılan, birden fazla cihazı eş zamanlı veya aralarında geçişler yaparak kullanım oranının \%36 olduğu ve \%32,5 ile \%41 arasında bulunan gelişmiş ülkelerdeki kullanım oranları ile oldukça benzerlik gösterdiği görülmektedir (Brown, 2014). ÇMG kullanımının gençler arasında bu kadar popüler olmasını yordayan nedenleri derleyen bir çalışmada (İmren, 2019) ÇMG'nin daha fazla tercih edilmesinin yaş, cinsiyet (Hwang, Kim ve Jeong, 2014), 1rk, eğitim ve gelir düzeyleri (Srivastava, Nakazawa ve Chen, 2016) ve kişilik özellikleri (Hwang vd., 2014) ile kısıtlı zamanda işleri halletme, sıkılma veya sabırsız hissetme ve yalnızlık (Tokan, 2011) gibi motivasyonların olduğu bildirilmiştir. Öte yandan, ÇMG kullanım oranının olası çıktılarını araştıran çalışmalar da alan yazında artış 
göstermiştir. Özellikle de ÇMG kullanımının bilişsel yetilerle ilişkisine dair araştırmalar yoğunluk göstermektedir.

Teknolojik yeniliklerle bezenmiş dijital çevrenin, özellikle bu çevreye adapte olarak büyümüş olan gençlerin (Choudhury ve McKinney, 2013) paralel işlemleme yetisi kazanmalarını sağladığı ve böylelikle gençlerin birden çok teknolojik ürünü veya aynı cihazdaki birden çok fonksiyonu birlikte kullanabildikleri düşünülmektedir (Small ve Vorgan, 2008). ÇMG, hem cihazlar veya fonksiyonlar arasında hem de görevle ilgili mental set (Monsell, 2003) üzerinde değişim yapma, hedefe odaklanma, ilgisiz bilgi ve uyaranları filtreleme, göreve uygun olmayan tepkileri ketleme, elde edilen bilgileri güncelleme gibi bilişsel işlevlerin kullanımını gerektirdiğinden, bilişsel kontrol yetisinin etkin kullanımına ihtiyaç duymaktadır (Altman ve Gray, 2008; Dzubak, 2008; Lin, 2009; Ophir, Nass ve Wagner, 2009; Schubert, 2008). Bu nedenle, özellikle ÇMG ve bilişsel kontrol bileşenleri ile ilişkisine odaklanan çalışmalar popülerliğini korumaktadır.

Bilişsel kontrol terimi başlarda daha çok dikkatin kapsamlılı̆̆ (extensiveness) ve seçiciliği ile boyutlandırılmış ve süreklilik gösteren süreçler anlamında ele alınmıştır (Gardner, Holzman, Klein, Linton ve Spence, 1959). Daha sonraları bilgi edinme ve edinilen bilginin kontrolü kapsamında araştırılmıştır (Hammond ve Summers, 1972). Son zamanlarda ise, yönetici işlevler veya yönetici kontrol olarak da adlandırılabilen (Diamond, 2013; Mackie, Dam ve Fan, 2013) bilişsel kontrol yetisinin bileşenleri olarak, ketleme, esneklik/değişim, çalışma belleği ve hedefe odaklanma/hedefi sürdürme (Amer, Campbell ve Hasher, 2016; Barroulllet ve Camos; 2010; Braver ve Cohen, 2001; Friedman ve Miyake, 2017; Miller, 2000; Morton, Ezekiel ve Wilk, 2011; Diamond, 2013; Mackie vd., 2013) ve daha üst düzey bilişsel yetiler olan planlama, problem çözme, çoklu görev sürdürme gibi bilişsel işlevler ele alınmaktadır (Burgess, Veitch, De lacy Costello ve Shallice, 2000; Chan, Shum, Toulopoulou ve Chen, 2008; Grafman ve Litvan, 1999). Bunların dışında sınırlı kaynağın yönetilmesi, zor yeni karmaşı görevlerin çözülmesi alışkanlık haline gelen davranışın ketlenmesi (MacDonald, Cohen, Stenger ve Carter, 2000) ve hedef odaklı esnek zihinsel davranışın yönetilmesi (Ridderinkhof, Ullsperger, Crone ve Nieuwenhuis 2004; Somerville ve Casey 2010) gibi süreçlerle ilişkilendirilmiştir. Ayrıca, çoklu görevleri sürdürmede etkin olan bilişsel kontrol bileşenlerinin araştırıldığ 1 bazı çalışmalar da ek olarak bilişsel control yetisinin çakışma takibi (conflict monitoring) (Botvinick, Barch, Carter ve Cohen, 2001; Gbadeyan, McMahon, Steinhauser ve Meinzer, 2016) ile dikkati yönetme (Chan vd., 2008; Norman ve Shallice, 1986) rollerine de vurgu yapılmıştır. Genel bir tanım ile bilişsel kontrol yetisi; dikkatin hedef görev ile alakalı olan bilgiye odaklanması, ilgili bilginin çalışma belleğinde tutulması ve ilgisiz olan bilgilerin filtrelenmesi, göreve uygun olmayan tepkilerin ketlenmesi gibi işlevleri sağlamakta, (Amer vd., 2016) hedef odağını kaybetmeden değişen durumlara esnek zihinsel tepki verebilmeyi mümkün k1lmaktadır (Altmann ve Gray, 2008; Banich, 2009; Gbadeyan vd., 2016; Miller ve Cohen 2001). ÇMG ve bilişsel kontrol üzerine yapılan çalışmalarda bilişsel kontrol yetisi genellikle ketleme, esneklik-değişim, çalışma belleği ve hedefe odaklanma bileşenleri üzerinden ele alınmıştır.

\section{Çoklu Görevler: Teorik Arka Plan}

ÇG alan yazını incelendiğinde, psikolojik tepkisizlik periodu (PRP) (Telford, 1931) deneylerinin çalışmalara öncülük yaptı̆̆ 1 açıkça görülmektedir (Meyer ve Kieras, 1997a). PRP, tepki verilmesi gereken iki uyaranın oldukça kısa aralıklarla $(500 \mathrm{~ms})$ sunulması durumunda, ateşlenmiş olan nöronun tekrar ateşlenmesi için gerekli olduğu varsayılan süre dolasıyı ile ikinci tepkinin, birinci tepkinin bitmesini beklemesi olarak tanımlanmaktadır (Telford, 1931). Deney sonuçları, Craik (1948) ve Welford (1952) gibi araştırmacıların ilgisini çekmiş ve eşzamanlı görevlerle ilgili deneyler artış göstermiştir. Aynı zamanda eşzamanlı görevlerle ile ilgili açıklayıcı görüş ve teoriler ortaya atılmıştır. Önceki teoriler zihnin tek kanala sahip olduğu vurgusunu yapmışlardır (Craik, 1948; Welford, 1952). Eş zamanlı ÇG kullanımında performans düşüşleri ve sıralı görevlere nazaran görevin tamamlanmasında görülen süre artışı, sınırlı zihinsel kapasite görüşleri için destek noktası olarak görülmüştür. Tek kanal görüşlerini darboğaz görüşleri izlemiştir (Broadbent, 1958; Pashler, 1994). Pashler (1994) laboratuvar ortamında kullanılan basit birtakım görevlerde (stop-sinyal, flanker görevi gibi) dahi bireylerin ikili görevleri sürdüremediğini ortaya koymuş ve bu durumun temelde zihnin tek 
bir darboğaza sahip olduğunu kanıtladığını öne sürmüştür. Ek olarak, çoklu görevler için darboğazın yapısal veya kaçınılamaz olmaktansa iki görevin önlenemez şekilde birbirini engellediği durumlarda ise stratejik bir durum olabileceğini vurgulamıştır. Darboğaz görüşlerinin PRP fenomenini açıklamada yetersiz olduğunu öne süren Kahneman (1973) zihnin uyaranlardan gelen girdilerin alındığı ve tepkilerin verildiği tek ve sınırlı bir kaynağa sahip olduğu ve birden fazla görev olması durumunda, bu sınırlı tek kaynak nedeniyle görevlerin eş zamanlı sürdürülemediğini öne sürmüştür (aktaran Borst, Taatgen ve Rjin, 2010). Fakat bazı görevlerin eşzamanlı olarak da sürdürülebiliyor olması, birden çok kaynak arasında varsayılan bir mükemmel zaman paylaşımı (perfect-time sharing) (Welford, 1984) olduğu fikrine yol açmıştır. Bu fikir, zihnin sınırlı kapasitesi dâhilinde birden fazla kaynağın paylaşılarak bazı görevlerin eşzamanlı olarak da yürütülebileceğini öne süren çoklu kaynak teorileri (multiple-resource theory) ile de örtüşmektedir (Navon ve Gopher, 1979; Wickens, 2002). Ancak, bu görüş sonraki teoriler tarafından hem bilişsel kapasiteye hem de bu kapasitenin bölüştürülmesine dair ayrı bir tanım veya modüle ihtiyaç duyduğu yönünde eleştirilmiştir (Meyer ve Kieras, 1997a; Salvucci ve Taatgen, 2008).

Schubert (2008), sınırlı kapasiteye dair görüşlerin öne sürdüğü zihnin sadece sıralı işlemleme yapabileceği görüşlerinin de, eş zamanlı şekilde yürütülebileceğini öne süren görüşlerin de temelde bilişsel kontrol yetisinin devreye girdiğinin kanıtı olduğunu öne sürmektedir. Çoklu görevlerin bilişsel kontrolü üzerine ortaya atılmış olan teorilerin çoğu kapasite sınırlılığından söz etmiştir, fakat buradaki sınırlılığın kaynağının zihnin kontrol yetisinden mi yoksa genel yapısal bir sinırlılıktan mı kaynaklandığı açık değildir (Botvinick ve Cohen, 2014). Schubert (2008)'e göre tüm sınırlı kapasite görüşleri yapısal değil, bilişsel kontrol yetisinin kapasitesi ile ilgilidir. Botvinick ve Cohen (2014) de benzer şekilde beynin sahip olduğu yoğun nöral ağlar nedeniyle yapısal bir sınırlılık görüşüne karşı çıkmış ve bilişsel kontrolün, birden fazla görev isteminden kaynaklı çakışmaların çözümü değil kaynağı olduğunu vurgulamıştır.

PRP deneyleri ile başlayan çalışmalar zihin ve çalışma prensibini anlamada oldukça önemli bir adım atılmasını sağlamıştır (Pashler, 1994). Ayrıca, kaynaklar ve dar boğazların da ötesinde genellikle görevleri yürütmek için yönetici birtakım süreçlerin tanımlanmasına ihtiyaç duyulmuştur (Monsell ve Driver, 2000; Salvucci ve Taatgen, 2008). Bu ihtiyaç özellikle de eski yıllardaki zihinde var olduğuna inanılmış olan minyatür insan Homunculus'u tarihe gömmek için (Monsell ve Driver, 2000), zihinsel mekanizmayı anlama gerekliliğini doğurmuştur. Bu nedenle bilişimsel teori ve hipotezler ortaya atılmıştır. Araştırmacılar bu teori ve hipotezlerin de gelişimi ile birlikte, ÇG'yi açıklamak için de bu görüşlerden faydalanmıştır. Bu teori ve hipotezler; yönetici süreç/bütünleyici kontrol (Meyer ve Kieras 1997a; 1997b), zincirli biliş (Salvucci ve Taatgen, 2008) teorileri ve problem temsilleri darboğazı hipotezidir (Borst vd., 2010).

\section{Teoriler}

Merkezi kapasite kısıtlılığı görüşlerine karşı çıkan Meyer ve Kieras, (1997a) tarafından ortaya atılmış olan Yönetici Süreç/Bütünleyici Kontrol (YSBK) (Executive Process/Integrative ControlEPIC) teorisinde temel varsayımlardan biri, farklı bilişsel kaynakların kullanımını gerektiren görevlerin eş zamanlı olarak gerçekleştirilebilecek olmasıdır. Teoriye göre farklı görevler tarafından aynı bilişsel kaynağın kullanımı gerektiğinde görevler paralel şekilde yürütülememektedir. Buradaki darboğazın nedeni ise, zihinsel kapasitede değil motor ve algısal sistemlerdeki yapısal sınırlılığa dayanmaktadır. Ancak bu yapısal sınırlılığa sahip sistemlerin yol açtığı darboğaz, yönetici süreçler aracılığı ile üstesinden gelinebilir durumdadır. Bu süreçleri yürüten bilişsel işlemcinin, çoklu görevlerde görevler tek başına yapıllyormuş̧̧asına paralel şekilde yürütülmesini sağlayabileceğini öne sürülmüş̧ür. Algısal işlemci, farklı modalitelerden gelen uyaranları betimlemekte ve ilgili bilgileri çalışma belleğine göndermektedir. Motor işlemci ise, farklı tepki gerektiren (vokal, manuel vb.) görevleri eşzamanlı sürdürebilmekte, fakat aynı tür tepki gerektiğinde darboğaz oluşacağından tepki üretememektedir. $\mathrm{Bu}$ durumda bilişsel işlemci devreye girerek görevleri önem sırasına dizmekte ve görevlerin bu sırada uygulanması komutunu vermektedir. Ayrıca bilişsel işlemci de, denetsel kontrol (supervisory control) öğesi ile görevlerin uygun şekilde yürütülüp yürütülmediğinin denetimini ve zamanlama algoritmaları ile görevlerin sıralı veya eş zamanlı yürütülmesini sağlayabilmektedir. 
Kaçınılmaz çakışmalar için daha karmaşık ve bu görevlere özgü kurallar yönetici süreç tarafından geliştirilmektedir. Çalışma belleği ise, işlemcilerin görevleri sürdürebilmek için ihtiyaç duyduğu bilgileri kısa süreli ve sınırlı şekilde tutmaktadır. Daha sık verilen tepkiler daha kısa sürede verilirken, yeni tepki üretimi daha fazla hazırlama evresi gerektireceğinden tepki süresi daha fazla olacaktır. Bu varsayım alıştırma sonrası görevlerin daha hızlı yapılabilmesini açıklamaktadır. ÇMG açısından ele alınırsa, örneğin bilgisayarda bir belge hazırlarken eş zamanlı olarak telefondan mesaj yazılamayacağı aşikârdır, ancak telefonla konuşurken (tek elde veya hoparlör ile) klavye üzerinden yazı yazmak mümkündür.

Bilişimsel bir model olan Adaptif Düşünce Kontrolü-Rasyonel (Adaptive Control of ThoughtRational (ACT-R)), Anderson vd., 2004) modeli, çoklu görevlerin sadece sıralı şekilde yürütülmesini açıklayabilmektedir (Salvucci, 2005; Salvucci ve Taatgen, 2008; Salvucci ve Taatgen, 2011). Salvucci ve Taatgen (2008) bu modeli geliştirerek zincirli biliş teorisini (threaded cognition theory) ortaya koymuştur. $\mathrm{Bu}$ teoriye göre biliş, müsait olan kaynakları görevle ilişkili işlemlemede kullanan zincirlere sahiptir. Bu zincirlerin her biri birtakım görevleri sürdürmek için yeterli donanıma sahiptir. Her bir zincir aynı anda tek bir görevi sürdürebilse de birlikte eş zamanlı görevler gerçekleştirebilir, görev için gerekli bilişsel kontrol esnekliğini karşılayacak şekilde eklenebilir veya çıkarılabilirdir. Örneğin, hem yazı yazan hem dinleyen bir kişi görevlerin zorluğuna göre birine ağırlık verebilir ve bu süreci yönetebilir. Genellikle diğer yaklaşımlar çoklu görevlerin sürdürülmesini genel bir yönetici süreç üzerinden açıklarken, bu teori insanların hâlihazırda ÇG yetisiyle donanmış olduğunu ve bu nedenle yönetici veya denetleyici bir öğeye ihtiyaç duymayacağını öne sürmektedir. Mevcut teoride, iki adet çevresel (görsel ve motor sistemler) ve iki adet merkezi bilişsel (açık bellek ve işlemsel bellek) darboğaz tanımlamıştır. Bu görüşe göre, aynı kaynağın kullanımı durumunda YSBK teorisinde öne sürüldüğü gibi bir çakışma olacağı öngörülmektedir. Normal şartlarda, mükemmel zaman paylaşımı ile görevler eşzamanlı sürdürülebilir iken; binişiklik (overlaping) durumunda kontrol mekanizmaları arasında etkileşim ile görevler sıralı şekilde sürdürülebilecektir (Salvucci, Taatgen ve Borst, 2009; Salvucci ve Taatgen, 2008; Salvucci ve Taatgen, 2011). Zincirlerin müsait kaynakları ihtiyaç duyduğunda kullanıp, görev bittiği gibi bırakan liberal yönetici işlevler olarak tanımlanabileceğini dile getirmiştir. Aynı kaynak isteminden doğan çakışma durumunda ise iki zincir sıralı şekilde işlemlenirken; ikiden fazla zincir sırada olduğunda farklı kaynakları işlemlemesi en yakın zamanda bitmiş olan zincir öne geçmektedir. $\mathrm{Bu}$ cimri yöntem zincirler arası dengeyi sağlamada kullanılmaktadır. YSBK teorinin aksine, zincirli biliş teorisi paralel değil dizisel işlemlemeye izin vermektedir. Araştırmacılar, teorilerini bir aşçının mutfaktaki mesaisinden bir kesitle örneklendirmişlerdir (Salvucci ve Taatgen, 2011). Bu örneğe göre, balık ve makarna siparişini hazırlayan aşçı, firını 1sıtırken bir yandan da makarna için su kaynatabilir. Ancak iki işlem aynı anda bittiğinde eş zamanlı olarak firına balığı, suya makarnayı atamayacağından aşçı kendi başına bir darboğaz temsilidir. Aynı şekilde, aynı anda bir kek ve balık siparişi olduğunu düşündüğümüzde firın bir darboğaz olacaktır ve aynı kaynak isteminde görülecek olan kaynak limitini temsil edecektir. Bu gibi darboğaza takılan durumlarda işlemler sıralı şekilde gerçekleştirilmek durumunda olacak ve pişirme işleminin bitme süresinde gecikme yaşanacaktır. Bunun yanı sıra ilk defa yapılan veya tecrübesiz olunan bir sipariş için kullanılması gereken tarif ise daha fazla gecikmeye yol açacak olsa da pratikle birlikte bu süreç gitgide kısalacaktır. Bu örnekte merkezi prosedürel kaynak aşçı tarafından, diğer kaynaklar ise elde edilebilir olan pişirme gereçleri tarafından temsil edilmektedir. Tarif kitabından bakılarak yapılan yemeğin pratikle birlikte öğrenilerek kitaba gerek duyulmadan yapılması ise başta açık belleğe bağımlı olan sürecin prosedürel sürece dâhil edilmesini temsil etmektedir. Genel olarak tek kanal ve tek darboğaz yaklaşımlarına alternatif bir yaklaşım sunan bu görüşler, birden çok darboğazın varlığını göstermiştir. Ayrıca, aynı kaynakları kullanmayan eş zamanlı görev eşleşmelerinde paralel olarak işlemlemenin ve görevleri bu şekilde sürdürmenin de mümkün olabileceğini ileri sürmüşlerdir.

Yönetici kontrol süreci teorisi (Rubenstein, Meyer ve Evans, 2001), temelde siralı şekilde sürdürülen görevler (biri bitip, diğeri başlayan görevler) ve görev değişimi halinde kullanılan çoklu görevleri açıklamak amacıyla ortaya atılmıştır. Teoride görev süreci ve yönetici kontrol süreci olmak üzere iki aşama öne sürülmüştür. Görev süreci, uyaran ve tepki arasındaki direk ilişkiyi 3 aşamalı olarak düzenlemektedir. Öncelikle uyaranın tanımlanması aşamasında uyaranın sahip olduğu algısal 
özellikler işlemlenmekte ve tepki seçimi aşamasında aktif hale gelecek şekilde çalışma belleğinde depolanmaktadır. Tepki seçimi aşamasında mevcut bilgiye dayalı uygun olan tepki seçilmekte ve son aşamada tepki üretimi gerçekleşmektedir. Yönetici kontrol süreci ise, geçiş yapılan görevlerde devreye girerek süreci iki aşamalı olarak yönetmektedir. İlk aşamada görevlerin değişimi ile birlikte görevlere ait hedeflerin değişimi gerçekleşmektedir. Bu nedenle mevcut ve ileriki görevlerin sıralamasının takibi ve yeni göreve ait hedefin çalışma belleğinde güncellenmesi ile eski göreve ait hedef bilgisinin ketlenmesini içermektedir.

İkinci aşamada ise, değişen görevi sürdürmek için gerekli kural aktivasyonu ve önceki göreve ait kuralların ise baskılanması ve pasif duruma getirilmesini içermektedir. Bu aşamadan sonra tepki seçme aşaması devreye girmekte, geçiş için gerekli hedeflerin değişimi ve kuralların aktivasyonu sonrası uygun olan tepki seçilerek, tepki üretimi sağlanmaktadır. Görevlerin sürdürülmesi sırasında yaşanabilecek olası çakışmanın tepki seçimi aşamasında çalışma belleğindeki görevle ilgisiz tepkilerin de aynı anda uygun olmayan şekilde aktif olmasından kaynaklanabileceğini ve çözümün de kural aktivasyonu aşamasındaki gibi uygun olmayan tepkilerin baskılanarak aynı anda sadece bir göreve ait kuralın aktif olmasını sağlamak olduğunu vurgulamıştır.

Görevler arasındaki çakışmaların beyinde nasıl yönetildiği çakışma takibi (conflict monitoring) teorisinin konusudur. Botvinick ve arkadaşları (2001) tarafindan ortaya atılan teoride Berlyne (1960)' in çakışmaların kontrol mekanizmalarını harekete geçirmedeki etkisi görüşünü temel alınmıştır. Bu görüşü nöropsikolojik verilerle destekleyerek teorilerini ortaya koymuşlardır. Anterior singulat korteks (anterior cingulate cortex) (ASK), yapılan çalışmalar sonucunda bilişsel kontrol öğesi ile bağlantılı olduğu kanıtlanmış olan bir yapıdır. (Posner ve DiGirolamo, 1998; Nee, Wagner ve Jonides, 2007; Stuss ve Alexsander, 2007). Yapılan bu kapsamlı çalışmalarda çeşitli çakışma yaratan görev setlerinde ASK anlamlı şekilde daha fazla aktivasyon sergilemiştir. Bu sonuçlar, ASK'ın çakışma durumlarına tepki gösterdiğini ortaya koymuştur. Ayrıca ASK aktivasyonu ile ilişkili olan bilişsel kontrol ögesinin, aynı zamanda prefrontal korteks (PFK) ile de ilişkili olduğu bilinmektedir (Banich, 2009).

Bazı araştırmacılar (Duncan ve Owen 2000) PFK'nın kontrol mekanizmasında rol almadığını ileri sürmüş olsa da, hasarlı beyin çalışmaları ve beyin görüntüleme çalışmaları aksi yönde kanıtlar sunmuştur (Banich, 2009; Nee vd., 2007; Stuss ve Alexsander, 2007). Botvinick ve arkadaşları (2001) tarafından çakışma yaratacak Ericsen Flanker gibi görevlerle yapılan görüntüleme çalışmasında da, çakışma yaratan denemeler diğer denemelere göre açıkça daha fazla ASK aktivasyonuna neden olmuştur. Botvinick ve arkadaşları (2001) bilişsel kontrol öğesinin temelde esnek bir işlevi olduğunu, ancak bu işlevin eş zamanlı görevlerde aynı kaynağın kullanımı veya yoğun bilişsel kontrol isteminden kaynaklı çakışmalardan etkileneceğini ileri sürmektedir. Bilişsel kontrolün esnekliğini sınırlayan bu gibi durumlarda görevler de arka arkaya sıralanacaktır. Örneğin, aynı anda gerçekleşen farklı konuşmaları dinlemek veya br matematik problemi çözmeye çalışırken (basit dört işlem problemleri haricinde), sözlü olarak yöneltilen ve karmaşık olmayan bir soruya cevap vermek gibi görevler bilişsel kontrol esnekliğini sınırlayacaktır.

Sonuç olarak, çoklu görevlerde çakışma durumunda ASK bölgesi çakışmaya tepki vermekte ve bilişsel kontrolün çakışmayı çözmesi için harekete geçmesini sağlamaktadır. Aradaki bağlantı ise geribildirim döngüsü (feedback loop) sayesinde sağlanmaktadır. Özetle, bilişsel kontrol yetisi görevlerin sürdürülmesi sırasında meydana gelen çakışmaları çözmek için stratejik bir araç olarak görülmektedir (Botvinick ve Cohen 2014).

\section{Hipotezler}

Alan yazında mevcut çalışmalardan yola çıkılarak, ÇMG kullanımı ve bilişsel kontrol yetisi arasındaki olası ilişkinin yönü, işleyişi veya sonuçları hakkında ampirik olarak test edilmemiş çeşitli öneriler ortaya atılmıştır. Bunlardan ilki Ophir ve arkadaşlarının (2009) çalışmasına açıklama getirmek amacıyla ortaya atılmış olan geniş menzilliye karşı odaklanmış bilişsel kontrol (Lin, 2009), diğeri ise bilişsel kontrolde yayılmış dikkate karşı eğitilmiş dikkat hipotezleridir (Van der Schuur, Baumgartner, 
Sumter ve Valkenburg, 2015). Ayrıca bilişimsel ÇG teorilerinden zincirli biliş teorisini geliştirmeyi amaçlayan problem temsili darboğazı (problem state bottleneck) hipotezi (Borst vd., 2010) de ele alınacaktır.

Lin (2009), Ophir ve arkadaşlarının (2009) çalışmasını temel alarak geniş menzilliye karşı odaklanmış bilişsel kontrol hipotezini ortaya atmıştır. Söz konusu hipotezde, yüksek ÇMG kullanan bireylerin bilişsel kontrol yetileri ile ilgili olarak geniş menzilli bir bilişsel kontrol stratejisine vurgu yapılmıştır. Bu görüşe göre, yüksek ÇMG kullanıcıları çevrelerindeki görevle ilgili olan veya olmayan tüm uyaranlara dikkat yöneltmekte, işlemlemeye konu etmekte ve böylece andaki görevle ilgili olmayan tepkileri ketleyememektedirler. Çalışma bulguları da yüksek ÇMG kullanımı bildiren katılımcıların dikkatlerini belirli görevi sürdürmek için odaklamada, ilgisiz uyaranlardan gelen sinyalleri filtreleme, görevle ilgili bilgileri güncelleme, manipule etme, görevler arasında değişimleme yapma gibi bilişsel kontrol yetisi gerektiren görevlerde başarısız olduklarını göstermiştir (Ophir vd., 2009). Lin (2009)'e göre yüksek ÇMG kullanıcılarının dikkatlerini belirli bir anda tekil uyaranlara (ekran gibi) yöneltmek ve odaklamak yerine, birçok uyaranı içerecek şekilde geniş bir menzile yaymış olduklarından dolayı, tekil uyaranlara odaklanmalarını gerektiren görevlerde başarısız olmaktadırlar. Yapılan çalışmalarda yoğun bir medya çevresini benimsemiş olan katılımcıların genellikle günlük uyaran çevrelerinden farklı olarak, tek ekran üzerinde aynı anda tek bir görev yapılmasına imkân verilecek şekilde test edilmektedirler. Özellikle teknolojik bir çevrede büyüyen gençlerin bu çevre tarafindan geniş menzilli bilişsel kontrol yetisi içn yönlendirildiklerini öne sürülmüştür. Özetle, Lin (2009) hipotezinde ÇMG kullanımının bilişsel kontrol yetisinde daha geniş menzilli uyaran kontrolü stratejisine neden olabileceği ve böylelikle odaklanma gereken görevlerde zorluğa neden olacağı öne sürülmüştür.

Van der Schuur ve arkadaşları (2015) ise, bilişsel kontrolde yayılmış (scattered) ve eğitilmiş (trained) dikkat hipotezlerini ortaya atmıştır. Yayılmış dikkat hipotezi ÇMG'nin negatif etkilerine odaklanarak, bilişsel kontrolde önemli rolü olan süreçleri zorlayacağından, gençlerin bilişsel kontrol yetilerinde uzun vadede bir bozukluğa neden olabileceğini öne sürmektedir. Bunun aksine, eğitilmiş dikkat hipotezi ise, ÇMG'nin bilişsel kontrol üzerinde olumlu etkileri olduğunu öne sürmektedir. Farklı kaynaklardan gelen bilgilerle başa çıkmada ÇMG pratiğinin yardımcı olacağını ve kolaylaştırıcı bir etkiye neden olacağı öngörülmektedir. Özellikle de görev değişimi (task switching), ilgisiz uyaranı filtreleme gibi süreçler üzerinden eğitim sağlayarak, bilişsel kontrol üzerinde geliştirici etki yaratacağ düşünülmektedir (Van der Schuur vd., 2015).

Borst ve arkadaşları (2010) zincirli biliş teorisini, eklediği problem temsili darboğazı hipotezi ile geliştirmeyi amaçlamıştır. Zincirli biliş teorisindeki 2 merkezi bilişsel darboğaz olan açık ve işlemsel bellek darboğazlarına üçüncü olarak problem temsilleri darboğazını eklemiştir. Problem temsilleri bir görevi gerçekleştirmek için gerekli olan aracı (intermediate) temsilleri sürdürmektedir (Borst vd., 2010). Ayrıca bahsi geçen aracı temsillerin aynı anda tek bir kümesini (chunk) tutabilen bir arabellek rolüne sahiptir (Borst ve Anderson, 2017). Araştırmacılar problem temsillerini, açıklamak için basit denklem problemlerini tercih etmişlerdir. Örneğin, $\quad(4 a-2=6)$ işlemi için önce

$(4 a=8)$ ara işleminin yapılması ve zihinde tutulması gerekmektedir. Sonuca ulaşmak için depolanan bu arabilgiden yararlanmak gerekmektedir. Problem State görev temsillerini ve gerekli bilgileri kısa süreli olarak tutması nedeniyle çalışma belleğine benzetilmektedir ve zincirli biliş teorisinde eksik olduğu düşünülen bu öge bu hipotezde tamamlanmıştır. Borst ve diğerleri (2010) hipotezlerini test ettikleri deney sonuçlarında problem temsillerinin anlamlı şekilde çoklu görev interferansını açıkladığını ortaya koymuştur.

\section{Alan Yazın Özeti}

Filtreleme yetisi, içinde yaşadığımız dijital çevrede birçok uyarandan andaki görevle ilişkili olanların işlemlenmesinde önemli bir yetidir. Ancak, çalışmalar incelendiğinde, tutarlı bir şekilde yoğun ÇMG bildiren katılımcıların filtreleme yetisini ölçen görevlerde anlamlı şekilde daha düşük performans sergilediği açıkça görülmektedir (Cain, Leonard, Gabrieli ve Finn, 2016; Cain ve Mittrof, 
2011; Cardoso-Leite vd., 2016; Ophir vd., 2009). Yoğun medya çevresine maruz kalan veya böyle bir çevreyi tercih eden bireyler meşgul oldukları görevleri sürdürmek için görevle ilgili olmayan diğer uyaranları filtrelemek durumundadırlar. Ancak bunun aksine, çalışmalar genellikle bu uyaranların filtrelenmediğini veya filtrelenemediğini göstermiştir. Bu durum bazı çalışmalarda bir avantaj olarak ortaya çıksa da (Lui ve Wong, 2012), genel olarak dikkatin odaklanmasını gerektiren görevlerde başarısızlığa neden oluyor gibi görünmektedir. Lin (2009) ve Van der Schuur ile arkadaşlarının (2015) ortaya attığı hipotezler bireylerin bilişsel yetilerinin birçok uyaranı içerecek şekilde geniş menzilli veya yayılmış bir strateji izleyecek şekilde değişim gösterdiğini varsaymaktadırlar.

ÇMG kullanıcılarının çepeçevre sarıldıkları medya ürünlerinden gelen sinyallere maruz kalması kaçınılmazdır (Ralph, Thomson, Seli, Carriere ve Smilek, 2015). Bu kullanımları gerçekleştirebilmek için andaki göreve uygun tepki verilirken, göreve uygun olmayan tepkilerin de ketlenmesi gerekmektedir. Ketleme yetisi ile ilgili performansa dayalı çalışmalar farklı sonuçlar ortaya koymuştur. Birtakım çalışma sonuçları (Ophir, vd., 2009, Seddon, Law, Adams ve Simmons, 2018; Murphy, McLauchlan ve Lee, 2017) yüksek ve düşük ÇMG kullanıcıları arasında anlamlı bir fark olmadığını belirtirken, Baumgartner ve diğerleri (2014) ise yoğun ÇMG kullanımının ketleme yetisi ölçümüyle pozitif ilişkili olduğunu bildirmiştir.

Öz bildirim çalışmalarına bakıldığında ise, yoğun ÇMG kullanımının günlük yaşamda daha sık tepki ketleme problemleri ile ilişkili olduğu görülmektedir (Baumgartner vd., 2014; Magen, 2017). Çalışma bulguları yoğun ÇMG kullanıcılarının ketleme yetisini uygun şekilde kullanamadığını, bu yetiyi ölçen testlerde daha kötü performans sergilediklerini ve günlük yaşamlarında da problem yaşadıklarını göstermiştir. Rubenstein ve arkadaşları (2001) teorilerinde andaki görevle ilgili olmayan hedef ve kuralların ketlenmesi gerekliliğine vurgu yapmıştır. Bu nedenle sonuçların, interaktif yapısı nedeniyle yoğun uyaran bombandırmanı sunan ÇMG kullanımı sırasında sürekli değiş̧ebilen hedef ve kurallara tepkinin ketlenemediği anlamına geldiği de düşünülebilir. Ayrıca ÇMG kullanıcılarının laboratuvar testlerinde düşük performans sergilemesi, özellikle beyin görüntüleme çalışmaları ile ortaya konan yapısal farklılıklar veya Lin (2009) ve Van der Schuur ile arkadaşları (2015) tarafindan ortaya atılan hipotezlerin temel aldığı stratejik değişikliklerden de kaynaklanıyor olabilir.

Hedef odağını sürdürme yetisi ile ilgili çalışma bulguları, çoğunlukla yoğun ÇMG kullanımı ile olumsuz yönde ilişkili olsa da (Cardoso-Leite vd., 2016; İmren ve Tekman, 2019; Ophir vd., 2009; Ralph vd., 2014; Yap ve Lim, 2013) herhangi bir ilişki olmadığını gösteren bulgular da bulunmaktadır (Minear, Brasher, McCurdy, Lewis ve Younggren, 2013; Moisala vd., 2016; Ralph vd., 2015). Görüldüğü gibi çalışma sonuçlarının çoğunluğu yoğun ÇMG kullanımının hedef odağını sürdürme problemleri ile ilişkili olduğunu göstermektedir. Genel olarak elde edilmiş olan olumsuz sonuçlar (Cardoso-Leite vd., 2016; İmren ve Tekman, 2019; Ophir vd., 2009; Ralph vd., 2014), geniş menzilli bilişsel kontrol ve yayılmış dikkat hipotezlerini desteklemektedir.

ÇMG kullanımında görev ve medyaların değişimlenmesi ile birlikte zihinsel olarak görev setleri arasında da geçişler yapıldığı düşünülmektedir (Monsell, 2003). Ancak mevcut çalışma bulguları ÇMG için elzem olduğu öne sürülen görev değişimi yetisi ile ilgili birbirinden farklı sonuçlar ortaya koymuştur. Çalışma bulgularının çoğunluğu, görev değişimi ve ÇMG kullanım yoğunluğunun negatif yönde ilişki olduğunu bulmuş olsa da (Cardoso-Leite vd., 2016; Ophir vd., 2009) herhangi bir ilişki olmadığını (Baumgartner vd., 2014; Seddon, vd., 2018) veya pozitif yönde ilişkili olduğunu (Alzahabi ve Becker, 2013) gösteren çalışmalar da bulunmaktadır. Zincirli biliş teorisine göre, bilişsel zincirler mevcut bilişsel kaynakları ihtiyaç olduğunda kullanan ve işlem bittiğinde ise serbest bırakan liberal yöneticiler olarak tanımlanmaktadır. Alan yazında ÇMG ve görev değişimi arasında olumsuz ilişki bildiren çoğunluk çalışmalar, belki de ÇMG sırasında bilişsel zincirlerin kullanıyor oldukları kaynakları uygun zamanda kullanma ve bırakma konusundaki yönetim sürecinde yaşanan problemlere işaret ediyor olabilir.

Çalışma belleği, görevler sırasında bilgilerin geçici olarak bellekte tutulması ve gerekli hallerde manipüle edilebilmesini sağlamaktadır. Bu yönüyle çoklu görevleri sürdürmede önemli bir 
yetidir (Altman ve Gray, 2008; Banich, 2009; Miller ve Cohen 2001). Alan yazın bulguları incelendiğinde, hem öz bildirime dayalı çalışmaların hem de performansa dayalı çalışmaların önemli çoğunluğu yoğun ÇMG kullanımının düşük çalışma belleği performansı ile ilişkili olduğunu göstermiştir (Magen, 2017; Ophir vd., 2009; Ralph ve Smilek, 2017; Sanbonmatsu, Medeiros-Ward, ve Watson, 2013; Uncapher, Thieu ve Wagner, 2016). Ayrıca, farklı olarak yüksek çalışma belleği performansı ile ilişkili olduğunu (İmren ve Tekman, 2019) ve herhangi bir anlamlı ilişki olmadığını bildiren çalışmalar (Baumgartner vd., 2014; Cardoso-Leite vd., 2016; Edwards ve Shin, 2017; Minear vd., 2013; Wiradhany ve Nieuwenstein, 2017, Seddon, vd., 2018) da bulunmaktadır. Birbirinden farkl1 yönlerdeki bu karmaşık sonuçlar yönetici süreç/bütünleyici kontrol (Meyer ve Kieras, 1997a; Meyer ve Kieras, 1997b) ve yönetici kontrol süreci (Rubinstein vd., 2001) hipotezleri üzerinden ele alınabilir. Meyer ve Kieras (1997a) çalışma belleği ögesinin farklı modelitelerden gelen bilgileri işlemlemesinin yanı sıra, ilgili işlemcilerin ihtiyaç duyduğu bu bilgileri kısa süreli depolama görevini de üstlendiğini belirtmektedir. Mevcut teoride sıkça verilen tepkilerin daha fazla pratik edilmesinden dolayı zamanla daha hızlı ve etkili bir şekilde yürütülebileceği öngörülmektedir. Daha fazla ÇMG bildiren bireylerin daha iyi çalışma belleği performansı ortaya koyduğunu bildiren sonuçlar da, ÇMG sırasında çalışma belleğinin sıklıkla geri getirdiği bilgilerin daha hızlı ve etkin şekilde çoklu görev sürdürmede bir alıştırma etkisi ortaya koyduğunu gösteriyor olabilir. Öte yandan, Rubenstein ve arkadaşları (2001) ise çakışmaların çalışma belleği ögesinde ilgisiz tepkilerin ketlenmediğine işaret ettiğini belirtmektedir. Daha fazla ÇMG bildiren katılımcıların düşük çalışma belleği performansı sergilediğini rapor eden çalışma sonuçları, çalışma belleğindeki görevle ilişkisiz tepkilerin ketlenmesinde bir problemi yansıtıyor olabilir. Sonuç olarak, alan yazındaki farklı sonuçların bireylerin çalışma belleğini aktif kullanmadaki bir takım etkili veya problemli stratejiler kullandığını veya ilgili yetiyi kullanmadaki başarı durumlarını yansıttığı düşünülebilir.

Beyin görüntüleme sonuçları ise, yoğun ÇMG kullanımının ASK' de gri madde yoğunluğunda azalma ile ve sağ PFK'de görülen daha fazla aktivasyon ile ilişkili olduğunu göstermiştir (Loh ve Kanai 2014; Moisala vd., 2016). Elde edilen sonuçlar, bilişsel kontrol gibi üst düzey bilişsel yetilerde rol oynayan prefrontal korteks (PFK) ile bağlantılı olan ASK'nin, bilişsel kontrol yetisi ile de ilişkili olabileceği şeklinde yorumlanmıştır (Cachia vd., 2013). Önceki çalışmalar da bilişsel kontrolde prefrontal bölgelerin rolünü göstermiştir (Kane ve Engle, 2002; Koechlin Ody ve Kouneiher; 2003; Schubert, 2008; Bunge ve Souza, 2009; Watson, Lambert, Miller ve Strayer, 2011; Sanbonmatsu vd., 2013). Bu nedenle elde edilen sonuçların, yoğun ÇMG kullanımının bilişsel kontrol yetisinin daha yoğun şekilde kullanımına ihtiyacı yansıttı̆̆ 1 şeklinde yorumlanabileceği düşünülmektedir. Görüldüğü üzere, çalışma sonuçlarına göre PFK ve ASK yoğun bilişsel kontrol gerektiren ÇMG kullanımı ile ilişkilidir. Bu sonuçlar, Botvinick ve arkadaşları (2001) tarafından öne sürülen çakışma takibi teorisi ile açıklanabilmektedir.

\section{Sonuç, Tartışma ve Öneriler}

Mevcut derlemenin amacı, çoklu medya görevlerinin bilişsel kontrol yetisi ile ilişkisini çoklu görev teori ve hipotezleri kapsamında değerlendirmektir. Literaürdeki deneysel, öz-bildirime dayalı ve beyin görüntüleme bulguları Yönetici süreç/bütünleyici kontrol, zincirli biliş teorileri ile problem temsilleri, geniş menzilliye karşı odaklanmış bilişsel kontrol, bilişsel kontrolde yayılmış dikkate karşı eğitilmiş dikkat ve problem durumu darboğazı hipotezleri üzerinden tartışılmıştır. Teori ve hipotezler genel olarak incelendiğinde, sonuçlar 1şığında ele alınabilecek birkaç ortak varsayımda bulundukları gözlenmiştir.

$\mathrm{Bu}$ varsayımlardan ilki, çoklu görevleri sürdürmek için merkezi bir bilişsel kontrol yetisinin gerekli olduğu varsayımıdır. Meyer ve Kieras (1997a, 1997b)' a göre çakışmaların çözümlenmesi, görevlerin denetlenmesi gibi hususlarda etkin olduğu varsayılan tek yeti, merkezi bilişsel kontrol yetisidir. Rubinstein ve arkadaşları (2001) da çoklu görevlerin değişimlemeli şekilde sürdürülmesinde merkezi bir bilişsel kontrol ögesi tanımlamıştır. Salvucci ve Taatgen (2008) ile Borst ve arkadaşları (2010) ise Zincirli Biliş Teorisi'nde, bireylerin hâlihazırda görevleri eş zamanlı olarak sürdürme yetisine sahip olduğunu, ancak çakışma durumlarına özgü üst bir bilişsel kontrol bileşeni yerine görevleri sürdürmek için gerekli kaynakların kullanımını sağlayan zincirlerin "liberal yönetici işlev" 
(Salvucci ve Taatgen, 2008) görevi gördügünü belirtmektedir. Zincirler çakışma durumunda prosedürel kaynak işlemlemesi en yakın zamanda bitmiş olan zincirin ihtiyaç duyduğu kaynağ 1 edinip, işlemleme bittiğinde bırakacağı bir anlaşmaya sahip gibi görünmektedir. ÇMG düşünüldüğünde de farklı kullanım fonksiyonlarına sahip olan en az biri medya içeren aktiviteler (Lang ve Chrazon, 2015) veya aynı cihazda farklı işlevler kullanılabilmektedir. Farklı görevlerin farklı mental setler gerektireceği (Monsell, 2003) düşünüldüğünde, bu görevlerin birlikte yürütülmesi farklı zincirler içeriyor ve böylece genel bir bilişsel kontrol yetisine ihtiyaç duyulmuyor olabilir. Bu ihtimal, elde edilen olumsuz sonuçlar için güçlü bir neden oluşturmasa da eski yetiler yerine tercih edilen yetilerin nöral bağlantıları güçlenirken (Uzbay, 2010) kullanılmayan bağlantıların zayıfladığı bilinmektedir (Small ve Vorgan, 2008; Choudhury ve McKinney, 2013). Bu anlamda genel bir bilişsel kontrol yetisinin ÇMG sürdürmede artık etkin olmadığı varsayılarak, Zincirli Biliş Teorisi'nin desteklenmiş olduğu düşünülebilir. $\mathrm{Bu}$ durumda yoğun ÇMG kullanımı, özel bilişsel kontrol süreçlerini kullandığından genel bilişsel kontrolü ölçen testlere uyum sağlamak zorlaşıyor olabilir. Bu tür bir varsayım, aynı zamanda merkezi bir bilişsel kontrol yetisini vurgulayan Çakışma Takibi Teorisi (Botvinick, vd., 2001), Geniş Menzilli ve Odaklanmış Bilişsel Kontrol (Lin, 2009) ile Yayılmış ve Eğitilmiş Dikkat hipotezlerine (Van der Schuur, 2015) de farklı bir boyut kazandıracaktır. Şöyle ki, yoğun ÇMG kullanımı sonucu bu bölgelerde gözlenen yapısal farklılıklar, çakışmalar sonucunda beyinde bilişsel kontrol bölgelerinin olumsuz yönde değişmiş olabileceği izlenimi vermiştir. İlgili beyin bölgelerinde yapısal değişimlere sahip bireylerin kontrol ögesini tam performans kullanamaması nedeniyle, birden fazla medyayı yoğun ve belki de kontrolsüz biçimde kullandıkları şeklinde de düşünülebilir (Ophir, vd., 2009; Lin, 2009; Van der Schuur, vd., 2015). Lin (2009) ve Van der Schuur ile arkadaşları (2015) bir anlamda farklılaşan bir bilişsel kontrol yetisinden söz etmektedirler. Bahsi geçen farklılaşma beyindeki yapısal değişimlerin veya hâlihazırdaki farklı yapısal özelliklerin tezahürü de olabilir. Sonuç olarak, beynin plastik yapısı sonucu değişim özelliği barındırması merkezi bilişsel kontrol yetisinin çalışma prensibini etkileyen bir değişimi yansıtıyor olabileceği gibi; zincirlere devredilen kontrol yetkisinin sonucu olarak artık tercih edilmeyen yetiye ilişkin olduğu kanıtlanmış beyin alanlarındaki nöral devrelerin zayıflamasını da temsil ediyor olabilir.

Diğer bir varsayım ise, çoklu görevlerin çakışma durumu dışında tamamen paralel şekilde yürütülebilir olmasıdır. Bu varsayım görevler arasında herhangi bir çakışma olmadığında, yani aynı girdi veya çıktı (tepki vb.) kaynağının kullanımı gerekmediğinde çoklu görevlerin paralel biçimde sürdürülebileceğini öne sürmektedir. Yapılan çalışmalar ÇMG kullanımı ile eş zamanlı görev performansı arasında anlamlı bir ilişki olmadığını göstermiştir (Moisala, vd., 2016; Alzahabi ve Becker, 2013). Ele alınan teorilerde ÇG'nin aynı kaynağın kullanımı dışında paralel şekilde yürütülebileceği varsayılsa da, medya ile sürdürülen ÇG çalışma sonuçlarına göre eş zamanlı olarak sürdürülememektedir. Çalışmalarda genellikle aynı tepkiyi, yani çakışan kaynak kullanımı gerektiren farklı uyaranların (sunulan harfin sesli/sessiz olması ve rakamın tek/çift olması durumunu belirli tuşlarla bildirme) kullanılmış olması nedeniyle paralellik varsayımının doğrulanmamış olabileceği düşünülmektedir (Pashler, 1994; Alzahabi ve Becker, 2013). İpucu uyaranı ile işaret edilen iki uzak noktadan birinde ortaya çıkabilecek hedef uyaranın tespit edilmesi durumunda tek tip tepki (space tuşu) verilmesi gerektiğinde, yüksek ÇMG grubu daha başarılı olmuştur (Yap ve Lim, 2013). Çalışmalarda kullanılan testlerde aynı tepkinin gerekliliği durumunda başarı sağlanmamış olabileceği ihtimali Yap ve Lim (2013)' in çalışma bulguları ile beraber değerlendirildiğinde aslında prosedürel dar boğaz tanımlayan Zincirli Biliş Teorisi'nin (Salvucci ve Taatggen, 2008; Borst, vd., 2010) desteklendiği düşünülebilir. Öte yandan ÇMG, anında tepki gerektirebilen interaktif bir süreç içermesi nedeniyle ÇG'den farklılaşmaktadır (Todorov, 2017). Bu anlamda çakışmalar, teorilerin öngördügünden çok daha yoğun ve karmaşık süreçler içeriyor olabilir. Böyle olması halinde ÇM görevlerinin eş zamanlı sürdürülememesi olası görünmektedir. Ancak aktif tepki veya çaba gerektirmeyen görevlerin birlikte sürdürülebilmesi de (müzik dinlerken, kitap okumak gibi) YSBK teorisinin açıklamaları ile örtüşmektedir. ÇMG alan yazınında kullanımların bu tür günlük yaşam kullanımlarını kapsamlı şekilde ölçmüyor olması (Lui ve Wong, 2012) ve nasıl eşleştirildiklerinin ve eşleştirilen aktivitelerin kullanım yoğunluklarının ayrı olarak analize dâhil edilmemesi nedeniyle herhangi bir ilişki gözlenmemiş de olabilir. 
Bilişsel kontrol yetisinin görevler arasındaki çakışmaların çözümünde etkin olduğu varsayılmaktadır. Çakışma Takibi Teorisi'nde (Botvinick, vd.,2001) açıķ̧a vurgulanan ve üzerinde durulan bilişsel kontrolün çakışmaları izleme ve çözmedeki rolü, diğer teoriler tarafından daha çok çakışmaların çözümü rolüne odaklanılarak desteklenmektedir. Çakışmaların bilişsel kontrolü devreye soktuğu (Botvinick, vd., 2001) ve böylelikle aynı kaynak isteminde bulunan görevlerin bazı teorilerde önem sırasına göre (Meyer ve Kieras, 1997a, 1997b), bazılarında ise işlemlenmesi en son bitmiş olan göreve özgü zincirin önceliği prensibine göre (Salvucci ve Taatgen, 2008) bir nevi ön tanımlı (default) şekilde anlaşması esasına dayalı olarak birbiri ardına sıralanmasıyla çakışma çözümünün gerçekleştiği öne sürülmektedir. ÇMG çalışmaları genel olarak yoğun ÇMG kullanımı ile görev değişimleme içeren test performanslarının olumsuz yönde ilişkili olduğu bulgularına sahiptir (Ophir, vd. 2009; CardosoLeite vd., 2016; Baumgartner vd., 2014).Ancak Alzahabi ve Becker'ın (2013) çalışmalarında elde ettikleri yoğun ÇMG kullanıcılarının ardı ardına sıralanmış görevleri değişimli sürdürmede daha iyi performans sergilediği bulgusu bu varsayımı destekler görünmektedir.

Çoklu görev teori ve hipotezlerinde ortak olduğu düşünülen bir diğer sayıltı ise çalışma belleğinin çoklu görevleri sürdürmede önemli bir role sahip olduğudur.Çalışma belleği görevle ilgili bilgilerin geçici olarak gündemde tutulması, güncellenmesi ve manipüle edilmesi gibi olanakları sebebiyle (Cowan, 1998; Baddeley ve Logie, 1999), birden fazla görevi sürdürmede önemli role sahiptir (Ackerman ve Beier, 2007; Colom, vd., 2010; Redick 2016). Ortaya at1lan teori ve hipotezlerden bazıları çalışma belleğini ana bir bileşen olarak ele alırken (Meyer ve Kieras, 1997a; Rubinstein, vd., 2001; Borst, vd., 2010; Lin, 2009; Van der Schuur, vd., 2015), diğerlerinin dâhil etmediği (Salvucci ve Taatgen, 2008) görülmektedir. Çalışma sonuçları genellikle, yoğun ÇMG kullanımı ile düşük çalışma belleği performansına işaret etmiştir. Bu sonuçlar, ÇMG kullanımında çalışma belleğindeki görevle ilgili kuralların güncellenmediğini, ilgisiz bilgilerin interferansa neden olduğunu (Rubinstein, vd., 2001) veya görevlerin karmaşıklığı nedeniyle gerekli problem temsillerinin çalışma belleğinin sınırlı kapasitesini aşıyor olduğunu (Borst, vd., 2010; Meyer ve Kieras, 1997a) gösteriyor olabilir. Diğer yandan ÇMG kullanım yoğunluğu ile ilişkili olmadığını gösteren çalışmaların niceliksel benzerliği de, çalışma belleğinin ÇG/ÇMG sürdürmede elzem bir rolü olmadığını (Salvucci ve Taatgen, 2011a, 2011b) veya ÇMG kullanımının neden olduğu öne sürülen değişime (Lin, 2009; Van der Schuur, 2015) tabi olmadığını gösteriyor olabilir.

ÇMG çalışmalarından beslenen hipotezler ise, yoğun ÇMG kullanımının bireylerin bilişsel kontrol yetilerini etkin kullanamamalarına yol açtı̆̆ını ve hatta bilişsel kontrol yetilerinin farklı bir strateji izlemesine neden olduğunu öne sürmektedirler. Böylelikle, birçok uyaran üzerinde bilişsel düzeyde eş zamanlı bir kontrol sağlayamaya çalıştıklarını ve bu yüzden tekil görevler içeren testlerde başarı gösteremediklerini iddia etmektedir.

Görüldüğü gibi ÇG teorileri genellikle, ÇG kullanımının bilişsel kontrol temelinde beyindeki hipotetik etkinliğine dair olup, ÇG kullanım yoğunluğunun bilişsel kontrol yetisiyle geliştirici veya bozucu yönde ilişkili olup olmadığı ile ilgili bir varsayım içermemektedir. Bu nedenle, mevcut sonuçların teorik arka planda değerlendirilmesi oldukça sınırlı kalmaktadır. Bu durumun, hem çalışmaların bu teorik varsayımlar gözetilerek yürütülmemiş olmasından hem de Çoklu görev teori ve hipotezlerinin ÇG'nin olası bilişsel sonuçlarına işaret eden varsayımlar içermemesinden kaynaklandığı düşünülmektedir. Dahası, çalışmalar bilişsel kontrol yetisinin içerdiği yetileri ayrı olarak araştırırken, ÇG teori ve hipotezleri bilişsel kontrolü bir bütün olarak ele almıştır. Çalışma sonuçları, bilişsel kontrol yetisi olarak bütün şeklinde ele alındığında da ÇMG yoğunluğu ve bilişsel kontrol yetisi arasındaki genel anlamda olumsuz yönde bir ilişki görüldüğü söylenebilir. Çakışma takibinde etkin rol aldığ1 öne sürülen bilişsel kontrol yetisinin (Botvinick, vd., 2001; Botvinick ve Cohen, 2014), interaktif doğası gereği birçok çakışma içerdiği varsayılabilecek olan ÇMG kullanımından doğan çakışmaları izlemede yetersiz kalıyor olabilir. Bu durumun nedeni olarak bilişsel yükün fazlalığı akla gelmektedir. Bilişsel yük teorisi, görevle ilişkili algısal yükün ilişkisiz bilgilerin yaratabileceği interferans gücünü arttırırken, bilişsel kontrol yetilerindeki bilişsel yükün bu gücü azaltacağını öne sürmektedir (Lavie, 2010; Lavie, Hirst, De Fockert ve Vidin, 2004). Ayrica eş zamanlı görevlerde doğal olarak artan bilişsel yük, bilişsel kontrol yetisini olumsuz yönde etkilemektedir (Brand- 
D’Abrescia ve Lavie, 2008; Lavie, 2010). Sonuçlar Lin (2009) ve Van der Schuur ile arkadaşlarının (2015) hipotezlerinde dile getirdiği şekilde yoğun ÇMG kullanımına adapte olan bilişsel kontrol yetisinin yayılmış veya geniş menzilli bir kontrol stratejisi izliyor olduğunu gösteriyor olabilir. Varsayılan stratejik farklılık beyin görüntüleme çalışmalarının gösterdiği gibi yapısal değişimlere neden olmuş veya hâlihazırdaki değişimlerden kaynaklanıyor da olabilir. Tüm bu yapısal değişimler belki de izlenen strateji değişikliği sonrası "kullan-ya-da-kaybet" (use-it-or-lose-it) fenomeninin ön gördüğü gibi kullanılmamış olan yetilerde birtakım nöral kayıplar meydana gelmiş ve bunun sonucu olarak da davranışsal testlerde kötü performanslar gözlenmiş olabilir (Choudhury ve McKinney, 2013).

İleriki çalışmalarda, literatürdeki sonuçların farklılıklarını açıklayabileceği düşünülen ÇMG tercihleri ve bilişsel kontrol yetilerindeki bireyler arası farklılıklar gözetilmelidir. Mevcut ÇG teorilerinin genellikle dar boğazlara odaklandıkları ve günlük ÇG'yi açıklamada yeterli olmadıkları öne sürülmektedir (Logie, Law, Travley ve Nissan, 2010; Todorov, 2017). Bu nedenlerle mevcut teorilerin ÇMG kullanımını da içerecek şekilde incelenmesi, geliştirilmesi ve test edilmesi önemlidir. Aynı zamanda, genel ÇG davranışını veya özel olarak ÇMG'yi zihinsel işleyiş, beyindeki aktivite ve kullanım düzeyinin olası sonuçları ile ilgili olarak mevcut teori ve hipotezlerden de faydalanılarak kapsayıcı bir model oluşturulabileceği düşünülmektedir. 


\section{Kaynaklar}

Ackerman, P. L. and Beier, M. E. (2007). Further explorations of perceptual speed abilities in the context of assessment methods, cognitive abilities, and individual differences during skill acquisition. Journal of Experimental Psychology: Applied, 13(4), 249.

Altmann, E. M. and Gray, W. D. (2008). An integrated model of cognitive control in task switching. Psychological Review, 115(3), 602-639.

Alzahabi, R. and Becker, M. W. (2013). The association between media multitasking, task-switching, and dual-task performance. Journal of Experimental Psychology. Human Perception and Performance, 39(5), 1485-95.

Amer, T., Campbell, K. L. and Hasher, L. (2016). Cognitive control as a double-edged sword. Trends in Cognitive Sciences, 20(12), 905-915.

Banich, M. T., (2009). Executive functions: The search for an integrated account. Association for Psychological Science, 18(2), 89-94.

Barrouillet, P. and Camos, V. (2010). Working memory and executive control: A time-based resourcesharing account. Psychologica Belgica, 50(3), 353-382.

Baumgartner, S. E., Weeda, W.D., Van Der Heijden, L. L. and Huizinga, M. (2014). The relationship between media multitasking and executive function in early adolescents. Journal of Early Adolescence, 34(8), 1120-1144.

Berlyne, D. E. (1960). McGraw-Hill series in psychology. Conflict, arousal, and curiosity. New York: McGraw-Hill Book Company.

Borst, J. P. and Anderson, J. R. (2017). A step-by-step tutorial on using the cognitive architecture ACT-R in combination with fMRI data. Journal of Mathematical Psychology, 76, 94-103.

Borst, J. P., Taatgen, N. A. and van Rijn, H. (2010). The problem state: A cognitive bottleneck in multitasking. Journal of Experimental Psychology. Learning, Memory, and Cognition, 36(2), 363-382.

Botvinick, M. M., Braver, T. S., Barch, D. M., Carter, C. S. and Cohen, J. D. (2001). Conflict monitoring and cognitive control. Psychological Review, 108(3), 624-652.

Botvinick, M. M. and Cohen, J. D. (2014). The computational and neural basis of cognitive control: Charted territory and new frontiers. Cognitive Science, 38(6), 1249-1285.

Brand-D'Abrescia, M. and Lavie, N. (2008). Task coordination between and within sensory modalities: Effects on distraction. Attention, Perception, \& Psychophysics, 70(3), 508-515.

Broadbent, D. E. (1958). Perception and communication. New York: Oxford University Press.

Brown, M. (2014). AdReaction: Marketing in a multiscreen world. Millward Brown Market Research Report.

Bunge, S. A. and Souza, M. J. (2009). Executive function and higher-order cognition. Neuroimaging, 4, 111-116. 
Burgess, P. W., Veitch, E., De Lacy Costello, A. and Shallice, T. (2000). The cognitive and neuroanatomical correlates of multitasking. Neuropsychologia, 38(6), 848-863.

Cachia, A., Borst, G., Vidal, J., Fischer, C., Pineau, A., Mangin, J. F. and Houdé, O. (2014). The shape of the ACC contributes to cognitive control efficiency in preschoolers. Journal of Cognitive Neuroscience, 26(1), 96-106.

Cain, M. S. and Mitroff, S. R. (2011). Distractor filtering in media multitaskers. Perception, 40(10), 1183-92.

Cain, M.S., Leonard, J.A., Gabrieli, J.D.E. and Finn, A.S. (2016). Media multitasking in adolescence. Psychonomic Bulletin \& Review, 1932-1941.

Cardoso-Leite, P., Kludt, R., Vignola, G., Ma, W. J., Green, C. S. and Bavelier, D. (2016). Technology consumption and cognitive control: Contrasting action video game experience with media multitasking. Attention, Perception, \& Psychophysics, 78(1): 218-241.

Chan, R. C. K., Shum, D., Toulopoulou, T. and Chen, E. Y. H. (2008). Assessment of executive functions: Review of instruments and identification of critical issues. Archives of Clinical Neuropsychology, 23(2), 201-216.

Choudhury, S. and McKinney, K. A. (2013). Digital media, the developing brain and the interpretive plasticity of neuroplasticity. Transcultural Psychiatry, 50(2), 192-215.

Craik, K. J. W. (1948). Theory of the human operator in control systems. British Journal of Psychology. General Section, 38(3), 142-148.

Diamond, A. (2013). Executive functions. Annual Review of Psychology, 64(1), 135-168.

Duncan, J. and Owen, A.M. (2000). Common regions of the humanfrontal lobe recruited by diverse cognitive demands. Trends in Neurosciences, 23, 475-483.

Dzubak, C. M. (2008). Multitasking: The good, the bad, and the unknown. The Journal of the Association for the Tutoring Profession, 1(2), 1-12.

Edwards, K. S. and Shin, M. (2017). Media multitasking and implicit learning. Attention, Perception, \&Psychophysics.

Friedman, N. P. and Miyake, A. (2017). Unity and diversity of executive functions: Individual differences as a window on cognitive structure. Cortex, 86, 186-204.

Gardner, R. W., Holzman, P. S., Klein, G. S., Linton, H. B. and Spence, D. P. (1959). Cognitive control: A study of individual consistencies in cognitive behavior. Psychological Issues, 1(4), $1-186$.

Gbadeyan, O., McMahon, K., Steinhauser, M. and Meinzer, M. (2016). Stimulation of dorsolateral prefrontal cortex enhances adaptive cognitive control: A high definition transcranial direct current stimulation study. Journal of Neuroscience, 36(50), 12530-12536.

Grafman, J. and Litvan, I. (1999). Importance of deficits in executive functions. The Lancet, 354 (9194), 1921-1923.

Hammond, K. R. and Summers, D. A. (1972). Cognitive control. Psychological Review, 79(1), 58-67. 
Hwang, Y., Kim, H. and Jeong, S. (2014). Why do media users multitask? Motives for general, medium-specific, and content-specific types of multitasking. Computers in Human Behavior $36,542-548$.

İmren, M. (2019). Çoklu medya görevini yordayan değişkenler üzerine bir gözden geçirme. Nesne, 7(14), 136- 147.

İmren, M. and Tekman, H. G. (2019). The relationship between media multitasking, working memory and sustaned attention. Uluda ̈̆ Üniversitesi Fen-Edebiyat Fakültesi Sosyal Bilimler Dergisi, 20 (37), 1075-1100.

Jersild, A. T. (1927). Mental set and shift. Archives of Psychology, 14(89), 81.

Kane, M. J. and Engle, R. W. (2002). The role of prefrontal cortex in working-memory capacity, executive attention, and general fluid intelligence: An individual differences perspective. Psychonomic Bulletin \& Review, 9(4), 637-671.

Koechlin, E., Ody, C. and Kouneiher, F. (2003). The architecture of cognitive control in the human prefrontal cortex. Science, 302(5648), 1181-1185.

Lavie, N. (2010). Attention, distraction, and cognitive control under load. Current Directions in Psychological Science, 19(3), 143-148.

Lavie, N., Hirst, A., De Fockert, J. W. and Viding, E. (2004). Load theory of selective attention and cognitive control. Journal of Experimental Psychology: General, 133(3), 339.

Lin, L. (2009). Breadth-biased versus focused cognitive control in media multitasking behaviors. Proceedings of the National Academy of Sciences, 106(37), 15521-15522.

Logan, G. D. and Cowan, W. B. (1984). On the ability to inhibit thought and action: A theory of an act of control. Psychological Review, 91(3), 295.

Logie, R., Law, A., Trawley, S. and Nissan, J. (2010). Multitasking, working memory and remembering intentions. Psychologica Belgica, 50(3-4).

Loh, K. K. and Kanai, R. (2014). Higher media multi-tasking activity is associated with smaller graymatter density in the anterior cingulate cortex. PLOS ONE, 9(9), 1-7.

Lui, K. F. H. and Wong, A. C.N. (2012). Does media multitasking always hurt? A positive correlation between multitasking and multisensory integration. Psychonomic Bulletin \& Review, 19(4), $647-653$.

MacDonald, A. W., Cohen, J. D., Stenger, V. A. and Carter, C. S. (2000). Dissociating the role of the dorsolateral prefrontal and anterior cingulate cortex in cognitive control. Science, 288(5472), $1835-1838$.

Mackie, M.-A., Van Dam, N. T. and Fan, J. (2013). Cognitive control and attentional functions. Brain and Cognition, 82(3), 301-312.

Magen, H. (2017). The relations between executive functions, media multitasking and polychronicity. Computers in Human Behavior, 67, 1-9.

Meyer, D. E. and Kieras, D. E. (1997a). A computational theory of executive cognitive processes and multiple-task performance: Part 1. Basic mechanisms. Psychological Review, 104(1), 3-65. 
Meyer, D. E. and Kieras, D. E. (1997b). A computational theory of executive cognitive processes and multiple-task performance: Part 2. Accounts of psychological refractory-period phenomena. Psychological review, 104(4), 749.

Miller, E. K. (2000). The prefrontal cortex and cognitive control. Nature Reviews: Neuroscience, 1, $59-65$.

Miller, E. K. and Cohen, J. D. (2001). An integrative theory of prefrontal cortex function. Annual Review of Neuroscience, 24, 167-202.

Minear, M., Brasher, F., McCurdy, M., Lewis, J. and Younggren, A. (2013). Working memory, fluid intelligence, and impulsiveness in heavy media multitaskers. Psychonomic Bulletin \& Review, $20,1274-81$.

Moisala, M., Salmela, V., Hietajrvi, L., Salo, E., Carlson, S., Salonen, O. and Alho, K. (2016). Media multitasking is associated with distractibility and increased prefrontal activity in adolescents and young adults. NeuroImage, 134, 113-121.

Monsell, S. (2003). Task switching. Trends in Cognitive Sciences, 7(3), 134-140.

Monsell, S. and Driver, J. (Ed.). (2000). Control of cognitive processes: Attention and performance XVIII (Vol. 18). Cambridge: MIT Press.

Morton, J. B., Ezekiel, F. and Wilk, H. A. (2011). Cognitive control: Easy to identify but hard to define. Topics in Cognitive Science, 3(2), 212-216.

Murphy, K., Mclauchlan, S. and Lee, M. (2017). Is there a link between media-multitasking and the executive functions of filtering and response inhibition? Computers in Human Behavior, 75, $667-77$

Navon, D. and Gopher, D. (1979). On the economy of the human-processing system. Psychological Review, 86, 214-255.

Nee, D. E., Wager, T. D. and Jonides, J. (2007). Interference resolution: insights from a meta-analysis of neuroimaging tasks. Cognitive, Affective, \& Behavioral Neuroscience, 7(1), 1-17.

Norman, D. A. and Shallice, T. (1986). Attention to action: Willed and automatic control of behavior. In R. J. Davidson, G. E. Schwartz ve D. Shapiro (Eds.), Consciousness and self-regulation: Advances in Research and Theory. (s.1-18). New York: Plenum Press.

Ophir, E., Nass, C. and Wagner, A. D. (2009). Cognitive control in media multitaskers. Proceedings of the National Academy of Sciences, 106 (37), 15583-15587.

Pashler, H. (1994). Dual-task interference in simple tasks: Data and theory. Psychological Bulletin, $116(2), 220-244$.

Posner, M. I. and DiGirolamo, G. J. (1998). Conflict, target detection and cognitive control. The Attentive Brain, 401-423.

Ralph, B. C. W., Thomson, D. R., Cheyne, J. A. and Smilek, D. (2014). Media multitasking and failures of attention in everyday life. Psychological Research, 78(5), 661-669.

Ralph, B. C. W., Thomson, D. R., Seli, P., Carriere, J. S. A. and Smilek, D. (2015). Media multitasking and behavioral measures of sustained attention. Attention, Perception ve Psychophysics, 77(2), 390-401. 
Ralph, B. C. W. and Smilek, D. (2017). Individual differences in media multitasking and performance on the n-back. Attention, Perception, \& Psychophysics, 79(2): 582-592.

Ridderinkhof, K. R., Ullsperger, M., Crone, E. A. and Nieuwenhuis, S. (2004). The role of the medial frontal cortex in cognitive control. Science, 306(5695), 443-447.

Roberts, D. F., Foehr, U. G. and Rideout, V. J. (2005). Generation M: Media in the lives of 8-18 yearolds. Kaliforniya: Henry J. Kaiser Family Foundation.

Rubinstein, J. S., Meyer, D. E. and Evans, J. E. (2001). Executive control of cognitive processes in task switching. Journal of Experimental Psychology, 27(4), 763-797.

Salvucci, D. D. (2005). A multitasking general executive for compound continuous tasks. Cognitive Science, 29(3), 457-492.

Salvucci, D. D. and Taatgen, N. A. (2011). The multitasking mind. New York: Oxford University Press.

Salvucci, D. D. and Taatgen, N. A. (2008). Threaded cognition: An integrated theory of concurrent multitasking. Psychological Review, 115 (1), 101-130.

Salvucci, D. D., Taatgen, N. A. and Borst, J. (2009). Toward a unified theory of the multitasking continuum: From concurrent performance to task switching, interruption, and resumption. Chi, $1819-1828$.

Sanbonmatsu, D. M., Strayer, D. L., Medeiros-Ward, N. and Watson, J. M. (2013). Who multi-tasks and why? Multi-tasking ability, perceived multi-tasking ability, impulsivity, and sensation seeking. PLoS ONE, 8(1): e54402.

Seddon, A. L., Law, A. S., Adams, A. M. and Simmons, F. R. (2018). Exploring the relationship between executive functions and self-reported media-multitasking in young adults. Journal of Cognitive Psychology, 30(7), 728-742.

Schubert, T. (2008). The central attentional limitation and executive control. Frontiers in Bioscience, $13,3569-3580$.

Small, G. and Vorgan, G. (2008). iBrain: Surviving the technological alteration of the modern mind, New York: HarperCollins.

Somerville, L. H. and Casey, B. J. (2010). Developmental neurobiology of cognitive control and motivational systems. Current opinion in neurobiology, 20(2), 236-241.

Srivastava, J., Nakazawa, M. and Chen, Y. W. (2016). Online, mixed, and offline media multitasking: Role of cultural, socio-demographic, and media factors. Computers in Human Behavior, 62, 720-729.

Stuss, D. T. and Alexander, M. P. (2007). Is there a dysexecutive syndrome? Philosophical Transactions of the Royal Society B: Biological Sciences, 362(1481), 901-915.

Telford, C. W. (1931). The refractory phase of voluntary and associative responses. Journal of Experimental Psychology, 14(1), 1-36.

Todorov, I. (2017). Individual differences in multitasking: Support for spatiotemporal offloading. Department of Psychology, Stockholm University. Erişim adresi: http://www.divaportal.org/smash/record.jsf?pid=diva2:1068394 
Tokan, F. (2011). Media as multitasking: an exploratory study on capturing audiences' media multitasking and multiple media use behaviours, Master's Thesis, Aalto University, Aalto Economic Institute, Helsinki. Retrieved from http://urn.fi/URN:NBN:fi:aalto-201202231250

Uncapher, M. R., K Thieu, M. and Wagner, A. D. (2016). Media multitasking and memory: Differences in working memory and long-term memory. Psychonomic Bulletin \& Review, 23(2), 483-90.

Van der Schuur, W. A., Baumgartner, S. E., Sumter, S. R. and Valkenburg, P. M. (2015). The consequences of media multitasking for youth: A review. Computers in Human Behavior, 53, 204-215.

Watson, J. M. and Strayer, D. L. (2010). Supertaskers: Profiles in extraordinary multitasking ability. Psychonomic Bulletin \& Review, 17(4), 479-85.

Welford, A. T. (1952). The "Psychological refractory period" and the timing of high-speed performance: A review and a theory. British Journal of Psychology, 43(1), 2-19.

Wickens, C. D. (2002). Multiple resources and performance prediction. Theoretical Issues in Ergonomics Science, 3(2), 159.

Wiradhany, W. and Nieuwenstein, M. R. (2017). Cognitive control in media multitaskers: Two replication studies and a meta-Analysis. Attention, Perception, \& Psychophysics, 1-22.

Yap, J. J. Y. and Lim, S. S. W. H. (2013). Media multitasking predicts unitary versus splitting visual focal attention. Journal of Cognitive Psychology, 25(7), 889-902. 


\section{Extended Abstract}

It is thought that the digital environment created by the growth of technological innovations, enables younger people (Choudhury and McKinney 2013), who have grown up by adapting this environment, to gain parallel processing ability and thus they can use multiple technological devices or functions together (Small and Vorgan, 2008). MMT needs the effective use of cognitive control ability as it requires the use of cognitive functions such as changing both on the devices or functions and on the task-related mental set (Monsell, 2003), focusing on the target, filtering irrelevant information and stimuli, inhibiting improper responses, and updating the obtained data (Altman and Gray, 2008; Ophir et al., 2009; Lin, 2009; Dzubak, 2008; Schubert, 2008).

\section{Multitasking: Theoretical Background}

MT studies emerged from psychological refractory period (PRP) (Telford 1931) experiments (Meyer and Kieras, 1997a). PRP represents the time without response for neuron fire when two stimulus requiring behavioral response presented with short interstimulus interval $(500 \mathrm{~ms})$. The results of the experiment are interpreted as an indicator which shows that the mind has one channel. Low performance and increased task completion time during MT supported the limited capacity views. The bottleneck wievs ((Broadbent, 1958; Keele, 1973; Pashler, 1994) suggested that the mind has a bottleneck inhibiting dual task performance. For instance Pashler (1994) showed that participants failed on executing some basic tasks (e.g. stop-signal, flanker) simultaneously. Otherwise, the simultaneous sustainability of some tasks has led to the idea that there is an assumed perfect-time sharing (Meyer and Kieras, 1997a; Salvucci and Taatgen, 2008) among multiple sources. This idea also coincides with the multiple-resource theories, which suggest that multiple tasks can be carried out simultaneously by sharing multiple sources within the limited capacity of the mind. Later theories, however, have criticized this idea since it needs a further recognition or a module both for cognitive capacity and for the division of this capacity (Meyer and Kieras 1997a, 1997b). Researches have suggested various theories by using models to explain MT and the development of scientific models (Salvucci and Taatgen, 2008).

\section{Theories}

One of the main assumptions of executive process / integrative control (EPIC) theory suggested by Meyer and Kieras (1997a) is that tasks that require the use of different cognitive resources can be performed simultaneously. According to the theory, tasks cannot be conducted correspondingly when the use of the same cognitive resource is needed by different tasks. The reason of bottleneck here is not because of the mental capacity but because of the limitation in motor and perceptual systems.

According to threaded cognition theory of Salvucci and Taatgen (2008), cognition has threads that use available resources in task-related processing. Each of these threads is well qualified to carry out a number of tasks, and although each thread can achieve only single task at the same time, they can perform simultaneous tasks together, and they can be included or excluded according to the need of cognitive control flexibility.

The Executive Control Processes Model (Rubenstein, Meyer and Evans, 2001) has been introduced to explain the multiple tasks used mainly as sequential and as task switching. The model proposed two stages: the task process and the executive control process. The task process arranges the direct relationship between stimulus and response in 3 stages. In the response selection stage, the appropriate response based on the available information is selected and in the final stage, the response activation takes place.

The theory proposed by Botvinick, Braver, Barch, Carter and Cohen (2001) is based on Berlyne's (1960) idea on the effect of conflicts on activating control mechanisms. They have suggested the theory by supporting it with neuropsychological data. Anterior Cingulate Cortex (ACC) is a 
structure that has been approved to be related to cognitive control components (Posner and DiGirolamo, 1998; Nee, et al., 2007; Stuss and Alexsander, 2007 Cachia, et al., 2013).

\section{Hypotheses}

According to the view of Breadth-Biased versus Focused Cognitive Control (Lin, 2009), high MMT users pay attention to all stimuli around them even it is not related to the task, they involve them in the processing and therefore, they cannot inhibit responses which are not related to the current task.

Van der Schuur et al. (2015) have proposed scattered and trained attention hypotheses in cognitive control. The scattered attention hypothesis focuses on the negative effects of MMT as it challenges processes which have a significant role in cognitive control, and suggests that MMT causes a long-term lack in the cognitive control ability of younger people. On the other hand, the trained attention hypothesis indicates that MMT has positive effects on cognitive control.

Borst et al. (2010) have aimed to improve the threaded cognition hypothesis by adding the state bottleneck hypothesis to it. Problem state resource is used for maintaining intermediate task representations. (Borst et al., 2010), and also, it has the role of a cache memory holding a single chunk among mentioned resources at the same time (Borst and Anderson, 2017).

\section{Result and Discussion}

The results of the studies mostly indicate that cognitive control ability adapted to the intense use of MMT, which is suggested by Van der Schuur and her colleagues (2015), might follow a scattered control strategy. It is thought that the supposed strategic change might have caused structural changes and resulted from these changes as it has shown by neuroimaging studies. It can be assumed that all of these structural changes might have been the reason of certain neural losses in the abilities rarely used, as it is predicted by the phenomenon of use-it-or-lose-it, and as a result of this, poor performances in behavioral tests might be observed (Choudhury and McKinney, 2013). Besides, neuroimaging studies evidently support the conflict monitoring hypothesis of Botvinick and his colleagues (2001). Other models also make a supportive contribution to understand the outcomes of MMT behavior. Therefore, it is predicted that models, which are created by applying all these theories and hypotheses in the future, will make valuable contributions to the literature. 